\title{
Polar Coordinates based N-R Method for Load Modelling in Electrical Power Distribution Systems
}

\author{
VENKATASIVANAGARAJU.S*, M. VENKATESWARA RAO \\ Department of EEE, JNT University Anantapur, Ananthapuramu, \\ A.P, JNTUACEK, Kalikiri, Chittoor (Dt), A.P. \\ INDIA
}

\begin{abstract}
In this paper, load modelling has been done in electrical distribution system using local real time test data. This distribution system supplies base loads, residential, industrial, commercial and composite loads. Using power and current-mismatch functions in polar form, a comprehensive framework for applying the Newton-Raphson method to solve power flow problems is presented. The Newton-Raphson approach for solving power flow problems can be applied in six different ways using these two mismatch functions. For load (PQ)buses and generator (PV) buses, we propose a theoretical framework for analyzing these versions. In addition, we compare newly created versions of the Newton power flow method to current variants in this study. Numerical studies on distribution networks are used to study the convergence behavior of all approaches. The measurements are formed for short term load forecasting with different types of realistic loads such as base loads, residential, industrial, commercial and composite loads. The long-term load forecasting and their losses also has been performed along with short term load forecasting. The results are obtained and validated through MATLAB.
\end{abstract}

Key-Words: - Load modelling, Realistic loads, composite loads, OPF, MATLAB.

Received: May 21, 2021. Revised: November 26, 2021. Accepted: December 15, 2021. Published: December 31, 2021.

\section{Introduction}

Typical infrastructure, the process of estimating power consumption can be termed as load modelling, it can be of residential, industrial, commercial or agricultural [1]. In stability study, monitoring and safety of power system networks load modelling, identification plays an important role [2]. In design and modification of electrical distribution networks, the accurate load model is required [3-4]. The optimally model is difficult due to dynamic and nonlinear nature of electrical loads.

Load models are categorized into two types: stationary and active load models. In the stationary representations real, reactive powers express as a functions of bus voltage amplitudes and frequency. Resistive loads are one example of this concept. The active and reactive powers are expressed as a function of voltage and time in the dynamic load model category.[3] considers a composite load model that combines both static and dynamic models for proper system representation.

Static Load Model is not dependent on time and has been applied to represent static load apparatuses for a lengthy time and estimate dynamic load components. The models are expressed in exponential or polynomial form. These can be used in the investigation of symmetry condition of electrical power systems [5]. Some of models are categorized into Continuous Power $(\mathrm{P})$, Impedance $(\mathrm{Z})$ and current, subject to the power kin with voltage. In the exponential model, the load bus parameters such as voltage and power can be represented by exponential mathematical equations and is generally used to represent mixed load [6]. A dynamic model is important in voltage stability analysis and to represent active load model exponential recovery load model has to be used in [7].

The complex load model is additional type of model which contains of together static and dynamic load components. Literatures has been shows that the composite load models give more exact response when compares with static or active models [3]. In general, the power system load center comprises both static and dynamic loads and with this reason composite model gives accurate load representation in electrical distribution systems.

In case of decentralized areas, several consumers may contain induction motors in large numbers, it is not realistic to model each and every induction motor in the system. Hence, to represent a group of motors, single-unit models or aggregate models are needed 
with minimum order of induction motor [8]. The appropriate aggregation of dynamic load model minimizes the computation time and gives an efficient and faster model derivation. In [9], the authors has been proposed that small-scale aggregation model provides more accurate results when compares with the large scale aggregation model. Hence, considered a group of motors in place of single motors and then aggregate the model has been developed with the use of energy conservation law [8].

The increase in rapid energy generated from distributed energy resources accompanied by the system dynamics are often no longer negligible [10,11]. The authors have been proposed in [12-13], the models which are used for analysis or dynamic studies often very basic. At present, electrical distribution systems make use of dynamic loads such as electronic loads and induction motor loads. For precise modelling of dynamic response various compositions of the load has been taken into account. The distribution system feeder contains several types of motors, static and an electronic load in [14].

Based on the mathematical relations and physical behaviours of loads describe the functioning of electrical load devices which motivates measurementbased modelling [15]. To drive the load characteristics measurement-based modelling has been collects measurements. The advantage of this approach is collects data from the actual network, it has been applied to any load. The drawback in this approach is the developed model at one location of the network may not be useful at other locations. In [16], the authors have been introduced the advancements in developing load models and used the real time data for modelling by considering both consumer's behaviors and electrical characteristics [17].

Paper is organized that Section I gives the introduction of load models. Section II describes the proposed mathematical modelling and methodology and Results and discussions are presented in Section.

\section{N-R Method using Polar Coordinates}

The Newton-Raphson approach may be used to solve the power flow problem when the bus voltages are presented in polar form. In actuality, only the polar form is used in practise since it produces fewer equations than the total amount of equations in rectangular form.

The actual and reactive power flow on distribution lines, reactive power generator buses, and magnitude and phase angle of load bus voltages are among the findings of this study. The terms are confined to first order approximation in the NR technique of load flow analysis in equation employing Taylor's series expansion.

The non-linear equation leading power system are

$S_{i}=V_{j} I_{j}^{*}=P_{j}+j Q_{j}$

since $\mathrm{S}_{\mathrm{j}}=$ rectangular power in bus $\mathrm{j}$

$\mathrm{V}_{\mathrm{j}}=$ bus voltage at bus $\mathrm{j}$ specified as

$V_{j}=\left|V_{j}\right| e^{-i \sigma j}$

$V_{j}^{*}=\left|V_{i}\right| e^{-j \sigma i}$

$\sigma j=$ bus angle at node $\mathrm{j}$

$\sigma i=$ bus angle at junction $\mathrm{i}$

$V_{j}^{*}=$ rectangular bus voltage at junction $\mathrm{j}$

$V_{i}=$ bus voltage at $\mathrm{i}$

$I_{j}=$ The current injected into bus $j$, given by

$I_{j}=\sum_{k=1}^{n} V_{i} Y_{j i} ; \quad \mathbf{j}=\mathbf{1}, \mathbf{2}, \ldots, \boldsymbol{n}$

$Y_{j i}=\left|Y_{j i}\right| e^{-j \theta j i}$

$Y_{j i}$ is admittance at bus $\mathrm{j} \& \mathrm{i}$

$\theta \mathrm{ji}$ is admittance angle at junction $\mathrm{j} \& \mathrm{i}$

$P_{j}, Q_{j}$ is true and wattless power at bus $\mathrm{j}$

$S_{j}^{*}=V j * I j=P j-j Q j=$

$\sum_{k=1}^{n}\left|V_{j}\right|\left|V_{i}\right|\left|Y_{j i}\right| e^{-j\left(\theta_{j i}+\sigma_{j}-\sigma_{i}\right)}$

Distinct the conjugate rectangular power $S_{j}$

*, into true and imaginary power

$P_{j}=\sum_{i=1}^{n}\left|V_{j}\right|\left|V_{i}\right|\left|Y_{j i}\right| \cos \left(\theta_{j i}+\sigma_{j}-\sigma_{i}\right)$

Calculate, add $P_{j}$ for $\mathrm{j}=\mathrm{i}$ and for $\mathrm{j} \neq \mathrm{i}$
$P_{j}=V_{j}^{2} Y_{j j} \cos \theta_{j j}+\sum_{i=1, i \neq 1}^{n}\left|V_{j}\right|\left|V_{i}\right|\left|Y_{j i}\right| \cos \left(\theta_{j i}+\right.$ $\left.\sigma_{j}-\sigma_{i}\right)$

Similarly,

$Q_{j}=V_{j}^{2} Y_{j j} \sin \theta_{j j}+\sum_{i=1, i \neq 1}^{n}\left|V_{j}\right|\left|V_{i}\right|\left|Y_{j i}\right| \sin \left(\theta_{j i}+\right.$ $\left.\sigma_{j}-\sigma_{i}\right)$

Equa. 8 and 9 establish polar formula of OPF equations, deliver the considered values for total true power $P_{\mathrm{j}}$, reactive power $Q_{\mathrm{j}}$, incoming the system at bus I, representing designed values of $P_{\mathrm{j}} / P_{\mathrm{j}}$ cal and 
$Q_{\mathrm{j}} / Q_{\mathrm{j}}$ cal leads to the definition of mismatches $\Delta P \mathrm{j}$ and $\Delta Q \mathrm{j}$.

$\Delta P_{j}=P_{j} s c h-P_{j} c a l$

$\Delta Q_{j}=Q_{j} s c h-Q_{j}$ cal

$P_{j} s c h=P_{g j}-P_{d j}$

$Q_{j} s c h=Q_{g j}-Q_{d j}$

\section{Here}

$P_{\mathrm{j} s c h} \& Q_{\mathrm{j} s c h}$ are the net true, imaginary planned power inoculated into bus $\mathrm{j}$

$P_{g \mathrm{j}} \& Q_{g \mathrm{j}}$ denotes the planned true, imaginary produced power at bus $\mathrm{j}$.

$P_{d \mathrm{j}} \& Q_{d \mathrm{j}}$ represents the planned true and imaginary power demand at load bus $\mathrm{j}$.

Discrepancies happen when $P_{\mathrm{j} c a l}$ and $Q_{\mathrm{jcal}}$ do not match with the planned values.

The set of linear calculations articulating deviations in true and reactive power apparatuses of $\mathrm{V}_{\text {bus }}$ can be written in compact method as:

$\left[\begin{array}{l}\Delta P j \\ \Delta Q j\end{array}\right]=\left[\begin{array}{ll}J_{11} & J_{12} \\ J_{21} & J_{22}\end{array}\right]\left[\begin{array}{l}\Delta \sigma j \\ \Delta V j\end{array}\right]$

Where $J_{11}, J_{12} \ldots$ are as a separated matrix by resolution in

$\left[\begin{array}{ll}\frac{\partial \mathrm{P}}{\partial \sigma} & \frac{\partial P}{\partial|V|} \\ \frac{\partial Q}{\partial \sigma} & \frac{\partial Q}{\partial|V|}\end{array}\right]$

The $\sigma \mathrm{j}$ and $|\mathrm{Vj}|$, as proved by the following relationships.

$\mathrm{J}_{11}=\frac{\partial P}{\partial \sigma}\left[\begin{array}{ccc}\frac{\partial P j}{\partial \sigma j} & \cdots & \frac{\partial P j}{\partial \sigma n} \\ \vdots & \ddots & \vdots \\ \frac{\partial P n}{\partial \sigma j} & \cdots & \frac{\partial P n}{\partial \sigma n}\end{array}\right]$

$\mathrm{J}_{12}=\frac{\partial P}{\partial|V|}\left[\begin{array}{ccc}\frac{\partial P j}{\partial|V j|} & \cdots & \frac{\partial P j}{\partial|V n|} \\ \vdots & \ddots & \vdots \\ \frac{\partial P n}{\partial|V j|} & \cdots & \frac{\partial P n}{\partial|V n|}\end{array}\right]$

$\mathrm{J}_{21}=\frac{\partial Q}{\partial \sigma}\left[\begin{array}{ccc}\frac{\partial Q j}{\partial \sigma j} & \cdots & \frac{\partial Q j}{\partial \sigma n} \\ \vdots & \ddots & \vdots \\ \frac{\partial Q n}{\partial \sigma j} & \cdots & \frac{\partial Q n}{\partial \sigma n}\end{array}\right]$

$\mathrm{J}_{22}=\frac{\partial Q}{\partial|V|}\left[\begin{array}{ccc}\frac{\partial Q j}{\partial|V i|} & \cdots & \frac{\partial P j}{\partial|V n|} \\ \vdots & \ddots & \vdots \\ \frac{\partial Q n}{\partial|V j|} & \cdots & \frac{\partial Q n}{\partial|V n|}\end{array}\right]$
The explanation for $\Delta \sigma \mathrm{j}, \Delta V \mathrm{j}$ giving to eqn. 19 tends the correction to be useful to $|V \mathrm{j}|$ and $\sigma \mathrm{j}$.

$|V j|^{(a+1)}=|V j|^{(a)}+\Delta|V j|^{(a)}$

$\sigma j^{(a+1)}=\sigma j^{(a)}+\Delta \sigma j^{(a)}$

The Newton-Raphson method solves the polar form of the power flow equations until the mismatches at all buses fall within specified tolerances.

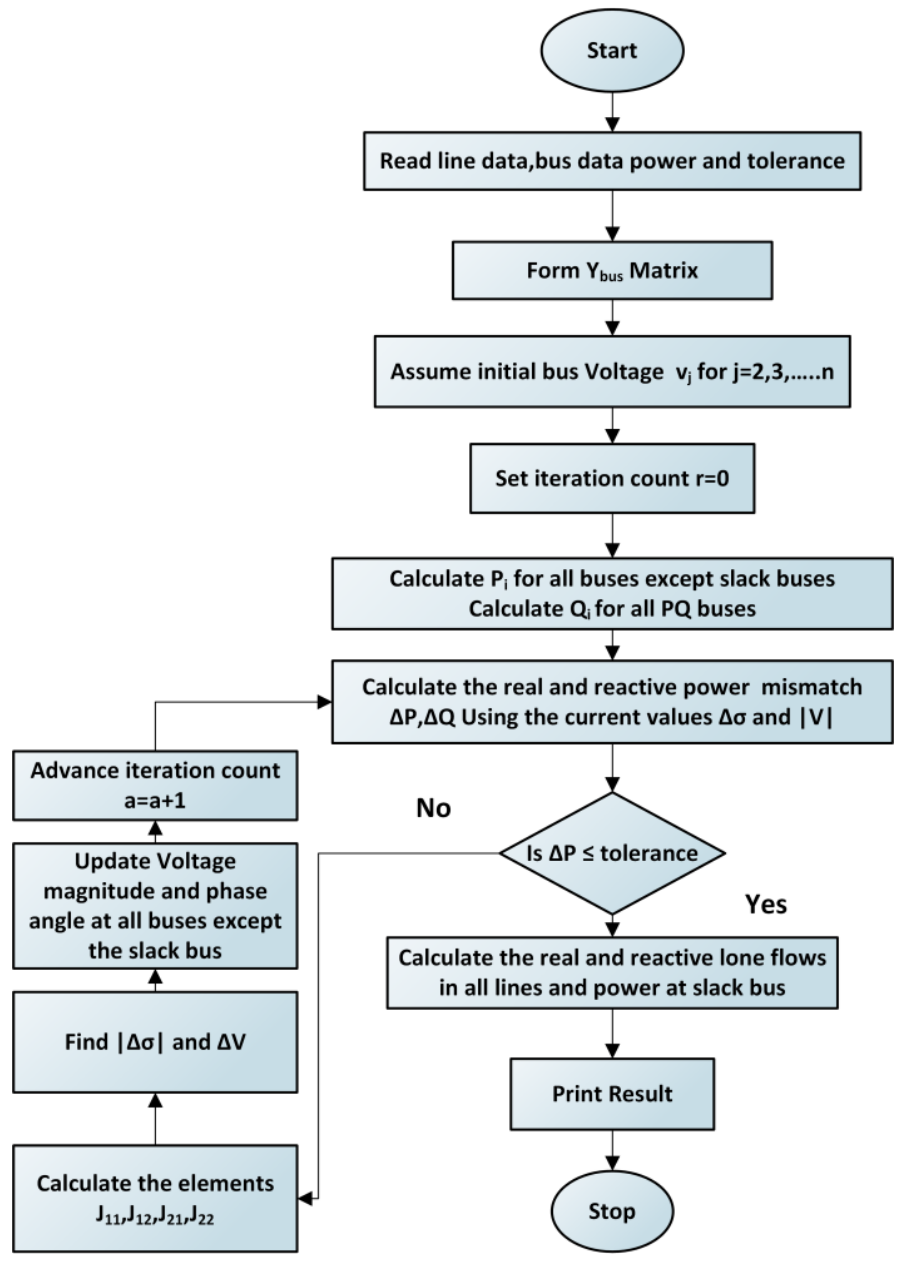

Figure 1. Flow Chart of Newton Raphson

\subsection{Algorithm of Newton Raphson}

STEP 1: Create the Y-bus matrix

STEP 2: Assume that the magnitude of the bus voltage, $|\mathrm{Vj}|$, and its phase angle, I are both equal to slack. quantities. In most cases, $|\mathrm{V} 1|=1.00 \mathrm{pu}$ and $1=0$ radians.

STEP 3: Set the iteration count to zero $(\mathrm{a}=0)$.

STEP 4: Using equations 20 and 21, calculate the real and reactive power for each load bus.

STEP 5: Using equations 22 to 25, calculate planned errors for each load bus. If a bus is powered by a 
generator (PV), Calculate only the change in real power because the value of reactive power is within its limits. If it goes beyond the bounds,

Then regard the limit that was breached as reactive power and treat it like a PQ bus.

STEP 6: Using the estimated $|\mathrm{Vj}|$ and I from step 2, calculate the Jacobian matrix elements.

STEP 7: Determine the values of $|\mathrm{Vj}|$ and I

STEP 8: Modify $|\mathrm{Vj}|$ and I at all loads using the values of $|\mathrm{Vj}|$ and I acquired in step 7. With the updated values of $|\mathrm{Vj}|$ and $\mathrm{I}$ begin the next iteration cycle at step 2.

STEP 9: Repeat until all planned errors for all load buses are under a given error tolerance, i.e., $\mathrm{Pj}(\mathrm{a}), \mathrm{Qj}$ (a), where $r$ is the load bus tolerance level.

STEP 10: Calculate the slack bus's line flows and power.

\subsection{Realistic Load Modelling}

In traditional load flow analyses, active and imaginary power needs are believed to have persistent values, independent of peak voltage on the same bus. Different types and classifications of loads may be present in actual power system operation. The active and reactive powers of these sorts of loads are dependent on the voltage and frequency of the system, and are evaluated in various design situations. Constant power, industrial, residential, and commercial loads are examples of realistic loads. The load models can be stated quantitatively as

$$
\begin{array}{r}
\mathrm{P}_{\mathrm{L}}=\mathrm{P}_{\mathrm{L}_{0}} \times\left(\frac{\mathrm{V}}{\mathrm{V}_{0}}\right)^{\alpha} \\
\mathrm{Q}_{\mathrm{L}}=\mathrm{Q}_{\mathrm{L}_{0}} \times\left(\frac{\mathrm{V}}{\mathrm{V}_{0}}\right)^{\beta}
\end{array}
$$

Where $\alpha$ and $\beta$ are the load exponents, and $\mathrm{P}_{\mathrm{L} 0}$ and $\mathrm{Q}_{\mathrm{L} 0}$ are the active and reactive power values at nominal voltages, respectively. The load bus voltage and nominal voltage are represented by $\mathrm{V}$ and $\mathrm{V}_{0}$, respectively. Table 1 shows the standards of the true, reactive proponents utilized in this study for industrial, domestic, and commercial loads.

Table 1. Real and reactive components

\begin{tabular}{|l|l|l|}
\hline Load component & $\alpha$ & $\beta$ \\
\hline Residential & 0.92 & 4.04 \\
\hline Industrial & 0.18 & 6.00 \\
\hline Commercial & 1.51 & 3.40 \\
\hline
\end{tabular}

\subsection{Load Growth}

For preparation and growth or well-organized operation of distribution networks, a system engineer should know the future estimation of the systems solutions. Load increase is modelled as follows in the suggested load flow algorithm:

$$
\text { Load }=\operatorname{Load} \times\left(1+\frac{g}{100}\right)^{\mathrm{n}}
$$

Where, ' $\mathrm{g}$ ' is the annual load growth rate of $7.5 \%$, ' $n$ ' is the No. of years

\subsection{Projected Approach}

In this presented manuscript, influence of different load representation is examined by implementing Chittoor District, APSPDCL distribution systems. Load flow analysis is performed for each load model. Ten years of past data is used to attain our required outputs. The impact of load models is examined by calculating active power loss $\mathrm{P}_{\mathrm{L}}$ and active power intake Pin take in tested distribution structure. The variance between characteristics is derived to appraise performance of load models for a tested distribution structure.

\subsection{Power Loss Reduction}

Through load flow analysis calculated the electric active power loss of the system expressed as:

$$
\mathrm{P}_{\mathrm{L}}=\sum_{i=1}^{n} i^{2} \mathrm{R}_{i}
$$

where $\mathrm{n}$ is the number of distribution system branches, $\mathrm{i}$ is the current flowing through each branch, and $\mathrm{Ri}$ is the resistance of each branch.

\subsection{Active power demand $\left(P_{\text {intake }}\right)$}

The active power intake Pin take can be calculated by adding power losses and true power demands by all buses in the distribution structure. This can be expressed by using the following equation:

$$
\mathrm{P}_{\text {intake }}=\mathrm{P}_{\mathrm{D}}+\mathrm{P}_{\mathrm{L}}
$$

\section{Results and Discussions}

\subsection{Time Variable Base Load Model}

It is apparent from Table 1, Figure 1 and Figure 2, the active power intake reduced significantly, active power loss reduction is depicted in Fig.2. Considerably there is a substantial decrease in MVA system for the whole period 


\subsection{Time Changing Demostic Load Model}

The analysis of Table 1, Fig.1 and 2 shows that as associated to base, commercial, composite load models' reduction of $\mathrm{P}_{\text {in }}$ take is lower but this difference is marginal in industrial load models. Furthermore, the reduction in Power loss is also lower with respect to remaining load models.

\subsection{Time Varying Industrial Load Model}

From Table 1, Fig. 1 and 2 for the industrial load model there is decrease in $\mathrm{P}_{\text {in }}$ take. The reduction of $\mathrm{P}_{\text {in }}$ take and power loss is slightly lesser than marketable and constant load representations, but in the domestic load model it is lower. Though, a considerable difference in reduction is observed in the case of composite load with $\mathrm{P}_{\text {in }}$ take and power losses.

\subsection{Time Variable Marketable Load Model}

In this situation, Fig. 1 and 2 demonstrates that the reduction in active power consumption is significantly more as associated to base, composite loads. observed a alike trend of decrease in Power loss with comparison of base and composite load models.

\subsection{Time Varying Composite Load Model}

It has shown from Fig. 1 and 2, the reduction in $\mathrm{P}_{\text {in }}$ take and power loss for time variable composite load model is significant less as associated to base, residential, industrial and commercial load models. However, from Fig 1 and 2 there exist decrease pattern of load models has an irregularity in the months.

Table 2. shows different load models such as base case, residential, industrial, commercial and composite and their losses for short term forecasting case from January 2020 to December 2020. In table 3, shown the measurements for long term load forecasting with the load growth and losses from the year 2020 to 2030 .

Table 2. Short term load forecasting and losses

\begin{tabular}{|l|l|l|l|l|l|l|l|l|l|l|}
\hline \multirow{3}{*}{ Month } & \multicolumn{3}{|l|}{ Base case } & \multicolumn{2}{l|}{ Residential } & \multicolumn{2}{l|}{ Industrial } & \multicolumn{2}{l|}{ Commercial } & \multicolumn{2}{l|}{ Composite } \\
\cline { 2 - 13 } & $\begin{array}{l}\text { Load, } \\
\text { MW }\end{array}$ & $\begin{array}{l}\text { Loss, } \\
\text { MW }\end{array}$ & $\begin{array}{l}\text { Load, } \\
\text { MW }\end{array}$ & $\begin{array}{l}\text { Loss, } \\
\text { MW }\end{array}$ & $\begin{array}{l}\text { Load, } \\
\text { MW }\end{array}$ & $\begin{array}{l}\text { Loss, } \\
\text { MW }\end{array}$ & $\begin{array}{l}\text { Load, } \\
\text { MW }\end{array}$ & $\begin{array}{l}\text { Loss, } \\
\text { MW }\end{array}$ & $\begin{array}{l}\text { Load, } \\
\text { MW }\end{array}$ & $\begin{array}{l}\text { Loss, } \\
\text { MW }\end{array}$ \\
\hline January & 1382.9 & 68.1722 & 1365.5 & 58.117 & 1367 & 58.796 & 1373.3 & 58.928 & 1386.4 & 69.105 \\
\hline February & 1385 & 68.6508 & 1367 & 58.339 & 1368.5 & 59.016 & 1374.7 & 59.14 & 1389.9 & 69.929 \\
\hline March & 1388.3 & 69.4707 & 1368.5 & 58.516 & 1370.1 & 59.215 & 1376.4 & 59.386 & 1390.6 & 70.141 \\
\hline April & 1389.9 & 69.9280 & 1368.6 & 58.471 & 1370.2 & 59.201 & 1376.8 & 59.438 & 1391.4 & 70.364 \\
\hline May & 1395.7 & 71.6703 & 1368.7 & 58.257 & 1370.6 & 59.105 & 1378.3 & 59.606 & 1391.8 & 70.493 \\
\hline June & 1397.1 & 72.0901 & 1368.7 & 58.196 & 1370.7 & 59.072 & 1378.6 & 59.639 & 1394.6 & 71.333 \\
\hline July & 1398.7 & 72.5862 & 1368.7 & 58.119 & 1370.7 & 59.028 & 1378.9 & 59.674 & 1397.8 & 72.296 \\
\hline August & 1399.9 & 72.9680 & 1368.6 & 58.056 & 1370.7 & 58.99 & 1379.2 & 59.698 & 1400.3 & 73.111 \\
\hline September & 1401.5 & 73.4871 & 1368.5 & 57.965 & 1370.6 & 58.933 & 1379.5 & 59.728 & 1405.7 & 74.912 \\
\hline October & 1404.5 & 74.5150 & 1368.1 & 57.767 & 1370.4 & 58.802 & 1380 & 59.771 & 1410.1 & 76.525 \\
\hline November & 1406.7 & 75.2814 & 1367.8 & 57.603 & 1370.2 & 58.687 & 1380.3 & 59.791 & 1415.5 & 78.755 \\
\hline December & 1413.2 & 77.7635 & 1366 & 56.97 & 1368.9 & 58.211 & 1380.8 & 59.776 & 1422.1 & 82.287 \\
\hline
\end{tabular}

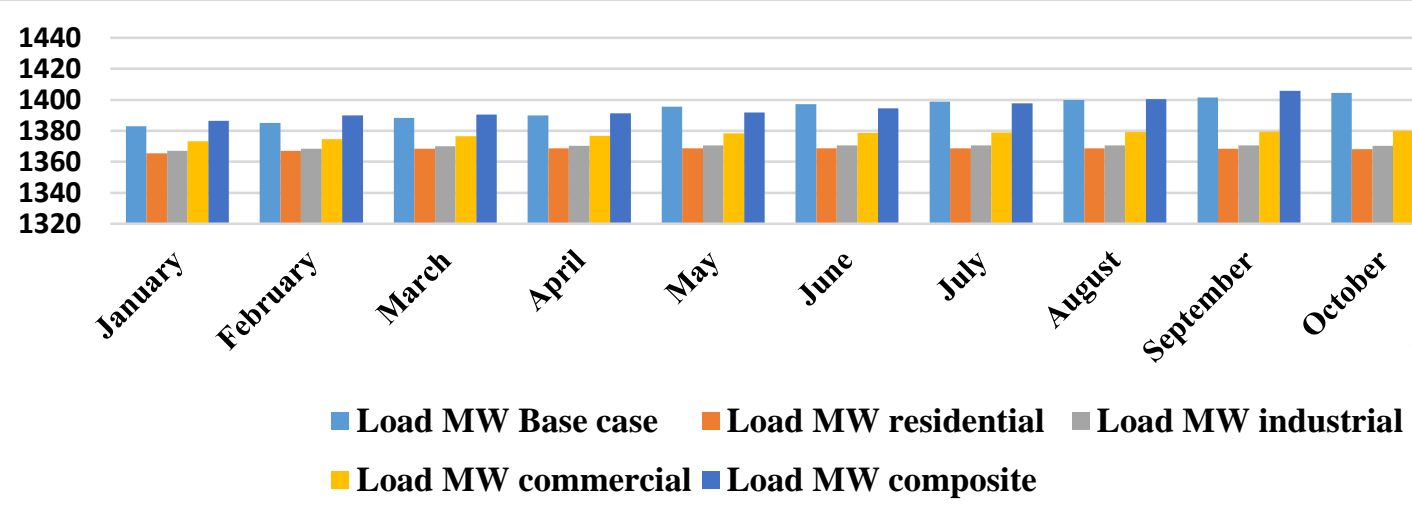

Fig. 2: Active Power demand V Months 
Table 3. Long term forecasting of loads and losses

\begin{tabular}{|c|c|c|c|c|c|}
\hline \multirow{2}{*}{ Year } & \multicolumn{2}{|c|}{ Base case } & \multicolumn{3}{|c|}{ Load growth } \\
\hline & $\begin{array}{l}\text { Load, } \\
\text { MW }\end{array}$ & $\begin{array}{l}\text { Loss, } \\
\text { MW }\end{array}$ & $\begin{array}{l}\text { Load, } \\
\text { MW }\end{array}$ & $\begin{array}{l}\text { Loss, } \\
\text { MW }\end{array}$ & Status \\
\hline 2020 & 1395.1 & 71.4698 & 1387 & 69.117 & Converged \\
\hline 2021 & 1401.3 & 73.4437 & 1392.6 & 70.715 & Converged \\
\hline 2022 & 1422.6 & 82.6578 & 1398.1 & 72.415 & Converged \\
\hline 2023 & 1395.4 & 71.5511 & 1403.7 & 74.245 & Converged \\
\hline 2024 & 1405.1 & 74.7140 & 1409.4 & 76.25 & Converged \\
\hline 2025 & 1416.6 & 79.2250 & 1415 & 78.52 & Converged \\
\hline 2026 & 1423.9 & 83.9394 & 1420.6 & 81.335 & Converged \\
\hline 2027 & 1421 & 81.5588 & 1426.3 & - & Diverged \\
\hline 2028 & 1418.5 & 80.1559 & 1432 & - & Diverged \\
\hline 2029 & 1424.3 & 84.6615 & 1437.8 & - & Diverged \\
\hline 2030 & 1408.2 & 75.8217 & 1443.5 & - & Diverged \\
\hline
\end{tabular}

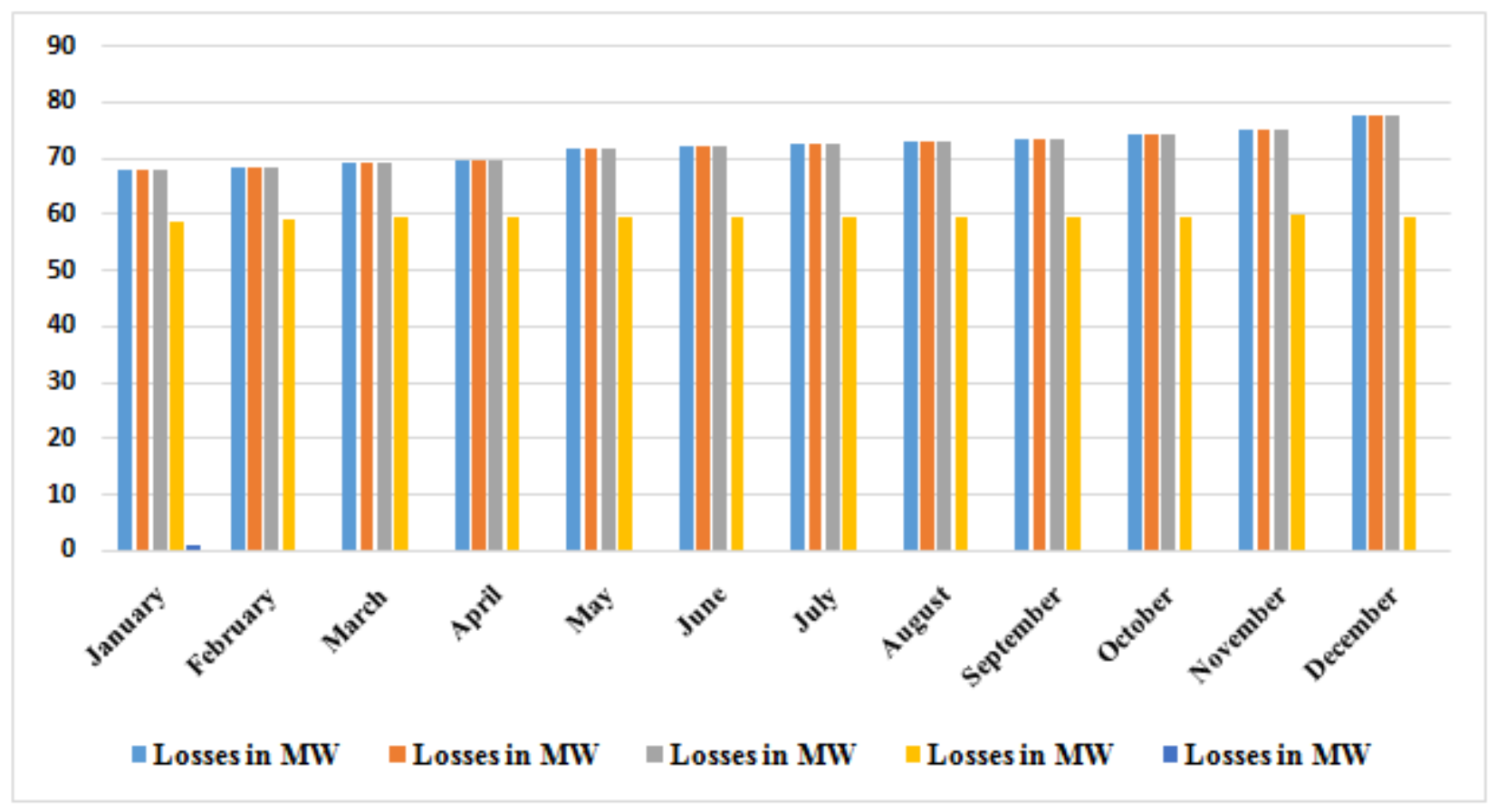

Fig. 3: Losses vs Months

\section{Conclusion}

The load modelling has been tested on realistic data from Local power distribution systems and builds the load with the proposed methodology which represents realistic loads effectively and procure operational characteristics of distribution systems. we compare newly created versions of the Newton power flow method to current variants in this study. Numerical studies on distribution networks are used to study the convergence behavior of all approaches. The measurements are formed for short term load forecasting with different types of realistic loads such as base loads, residential, industrial, commercial and composite loads. The long-term load forecasting and their losses also has been performed along with short term load forecasting.

\section{References:}

[1] Kontis, Eleftherios O., et al. "Measurement-based dynamic load modeling using the vector fitting technique." IEEE Transactions on Power Systems 33.1 (2017): 338-351. 
[2] Adianto, Yuana, et al. "The Coordinated Operation of Vertically Structured Power Systems for Electric Vehicle Charge Scheduling." Energies 15.1 (2022): 27.

[3] Chávarro-Barrera, L., S. Pérez-Londoño, and J. Mora-Flórez. "An Adaptive Approach for Dynamic Load Modeling in Microgrids." IEEE Transactions on Smart Grid (2021).

[4] Zhang Liang, Wang Gang, Giannakis Georgios B., "Real-Time Power System State Estimation and Forecasting via Deep Unrolled Neural Networks," IEEE Transactions on SP, vol.67, no. 15, pp. 4069-4077, 2019

[5] Wang, Ying, et al. "Online Realization of an Ambient Signal based Load Modeling Algorithm and its Application in Field Measurement Data." IEEE Transactions on Industrial Electronics (2021).

[6] Gao, Hao et al. "Building information modellingbased building energy modelling: A review." Applied energy 238 (2019): 320-343.

[7] Regulski P. et al., "Estimation of Composite Load Model Parameters Using an Improved Particle Swarm Optimization Method," IEEE Transactions on P.D, vol.30, no.2, 2015.

[8] Aree P., "Aggregating method of induction motor group using energy conservation law," ECTI Transactions on Electrical \& Computer Engineering, vol.12, no.1, pp.16, 2014.

[9] Muriuki JK, et al., "Comparison of aggregation of small and large induction motors for power system stability study," Global Engineers \& Technologists Review, vol.3, no.2, pp.9-13, 2013.

[10] Lew D et al., "The Power of Small: The Effects of Distributed Energy Resources on System Reliability," IEEE Power and Energy Magazine, vol. 15, no. 6, pp. 50-60, 2017.

[11] Eftekharnejad S, et al., "Impact of increased penetration of photovoltaic generation on power systems," IEEE Transactions on Power Systems, vol.28, no.2, pp.893-901, 2013.

[12] Milanovic JV, et al., "International Industry Practice on Power System Load Modeling," IEEE Transactions on Power Systems, vol.28, no.3, pp.3038-3046, 2013.

[13] Arif A, et al., "Load Modeling-A Review," IEEE Transactions on Smart Grid, vol.9, no.6, pp.5986-5999,2018.

[14] D.Krishna et al. "Adaptive FLC-based UPQC in distribution power systems for power quality problems." International Journal of Ambient Energy (2020): 1-11.
[15] S.H. Lee, S.E. Son, S.M. Lee, "Kalman-filter based static load modeling of real power system using K-EMS data," JEET, vol. 7, no. 3, pp. 304311, 2012.

[16] Aminifar, Farrokh, et al.,"State-of-the-Art in Synchro phasor Measurement Technology Applications in Distribution Networks and Microgrids." IEEE Access 9 (2021): 153875153892.

[17] D. Krishna et al, "Mathematical modeling and simulation of UPQC in distributed power systems," 2017 IEEE-ICEICE, 2017, pp. 1-5, doi: 10.1109/ICEICE.2017.8191886.

\section{Creative Commons Attribution License 4.0} (Attribution 4.0 International, CC BY 4.0)

This article is published under the terms of the Creative Commons Attribution License 4.0

https://creativecommons.org/licenses/by/4.0/deed.en_US 